University of Nebraska - Lincoln

DigitalCommons@University of Nebraska - Lincoln

Publications, Agencies and Staff of the U.S.

Department of Commerce

U.S. Department of Commerce

$10-2001$

\title{
Acoustic Detections of Singing Humpback Whales in Deep Waters Off The British Isles
}

\author{
Russell Charif \\ Bioacoustics Research Program, Laboratory of Ornithology, Cornell University, Sapsucker Woods Road, \\ Ithaca, New York, r.charif@cornell.edu \\ Phillip Clapham \\ Protected Species Branch, Northeast Fisheries Science Center, 166 Water Street, Woods Hole, \\ Massachusetts \\ Christopher Clark \\ Bioacoustics Research Program, Laboratory of Ornithology, Cornell University, Sapsucker Woods Road, \\ Ithaca, New York
}

Follow this and additional works at: https://digitalcommons.unl.edu/usdeptcommercepub

Part of the Environmental Sciences Commons

Charif, Russell; Clapham, Phillip; and Clark, Christopher, "Acoustic Detections of Singing Humpback Whales in Deep Waters Off The British Isles" (2001). Publications, Agencies and Staff of the U.S. Department of Commerce. 163.

https://digitalcommons.unl.edu/usdeptcommercepub/163

This Article is brought to you for free and open access by the U.S. Department of Commerce at DigitalCommons@University of Nebraska - Lincoln. It has been accepted for inclusion in Publications, Agencies and Staff of the U.S. Department of Commerce by an authorized administrator of DigitalCommons@University of Nebraska - Lincoln. 


\title{
ACOUSTIC DETECTIONS OF SINGING HUMPBACK WHALES IN DEEP WATERS OFF THE BRITISH ISLES
}

\author{
Russell A. Charif \\ Bioacoustics Research Program, \\ Laboratory of Ornithology, \\ Cornell University, \\ Sapsucker Woods Road, Ithaca, New York 14850, U.S.A. \\ E-mail: r.charif@cornell.edu \\ Phillip J. Clapham \\ Protected Species Branch, \\ Northeast Fisheries Science Center, \\ 166 Water Street, \\ Woods Hole, Massachusetts 02543, U.S.A. \\ Christopher W. Clark \\ Bioacoustics Research Program, \\ Laboratory of Ornithology, \\ Cornell University, \\ Sapsucker Woods Road, Ithaca, New York 14850, U.S.A.
}

\begin{abstract}
From October 1996 through September 1998, we used bottom-mounted hydrophone arrays to monitor deep-water areas north and west of the British Isles for songs of humpback whales (Megaptera novaeangliae). Singing humpbacks were consistently detected between October and March from the Shetland-Faroe Islands south to waters west of the English Channel. Temporal and geographic patterns of song detections, and movements of individually tracked whales, exhibited a southwesterly trend over this period, but with no corresponding northward trend between April and September. These results, together with a review of historical data from this area, suggest that the offshore waters of the British Isles represent a migration corridor for humpbacks, at least some of which summer in Norwegian (and possibly eastern Icelandic) waters. The migratory destination of the detected animals remains unknown, but the limited data suggest that these whales are bound primarily for the West Indies rather than historical breeding areas off the northwestern coast of Africa. Humpbacks detected in British waters after early to midMarch probably do not undertake a full migration to the tropics. These data provide further evidence that singing is not confined to tropical waters in winter, but occurs commonly on migration even in high latitudes.
\end{abstract}


Key words: humpback whale, Megaptera novaeangliae, song, migration, North Atlantic, Europe, Britain, acoustic monitoring, SOSUS.

The humpback whale (Megaptera novaeangliae) is a migratory baleen whale found in all the oceans of the world (see Clapham and Mead 1999 for a species review). Humpbacks migrate annually from summer feeding grounds in high latitudes to winter mating and calving areas in tropical or subtropical waters (Kellogg 1929, Dawbin 1966). Breeding is strongly seasonal and, with few known exceptions, occurs in winter (Chittleborough 1965, Nishiwaki 1966). In the western North Atlantic humpbacks feed in a variety of regions ranging from the northeastern United States to western Greenland (Katona and Beard 1990). In the eastern North Atlantic, feeding grounds occur in Icelandic and Norwegian waters (Christensen et al. 1992, Smith et al. 1999). There is strong maternally directed fidelity to specific feeding areas (Clapham and Mayo 1987, Katona and Beard 1990), and recent genetic work suggests that this fidelity has persisted on an evolutionary timescale in some areas (Palsbøll et al. 1995, Larsen et al. 1996).

Research based upon the photographic and genetic identification of individual humpbacks has shown that the primary migratory destination of whales from all of the western North Atlantic subpopulations (Gulf of Maine, Newfoundland/Labrador, Gulf of St. Lawrence, and Greenland) is the West Indies (Katona and Beard 1990, Palsbøll et al. 1997). Movements of individually identified whales between Iceland/Norway and the West Indies have also been documented (Martin et al. 1984; Palsbøll et al. 1997; Stevick et al. 1998, 1999). Historically important breeding grounds in the Cape Verde Islands and the eastern Caribbean appear to host relatively few whales today (Winn et al. 1975, Mitchell and Reeves 1983, Reiner et al. 1996), and the high-latitude summering grounds of animals found there in winter is currently uncertain.

The region north and west of the British Isles, although known as a historical habitat for humpback whales, has received little attention since the cessation of humpback whaling in this region in 1929. Between 1903 and 1929 a total of 76 humpbacks was taken by shore whaling stations off Britain and Ireland. The geographical distribution of these catches encompassed waters off the Shetland Islands, the Outer Hebrides, and the northwestern coast of Ireland (Fig. 1). Both Thompson (1928) and Ingebrigtsen (1929) considered the small catches of humpbacks to reflect the genuine scarcity of the species in this region rather than a preference by the whalers for other whales. In any event, the population identity and migratory destination of humpback whales off the British Isles are unknown.

Passive acoustic monitoring can be a useful complement to visual cetacean surveys because acoustic monitoring can be conducted $24 \mathrm{~h} / \mathrm{d}$, year round in a wide range of surface weather conditions, and because calling whales can commonly be detected at ranges exceeding the best visual detection limits by at least an order of magnitude (Clark and Ellison 1989, Norris et al. 1999). Bottom-mounted military hydrophone arrays (SOund SUrveillance System, or 


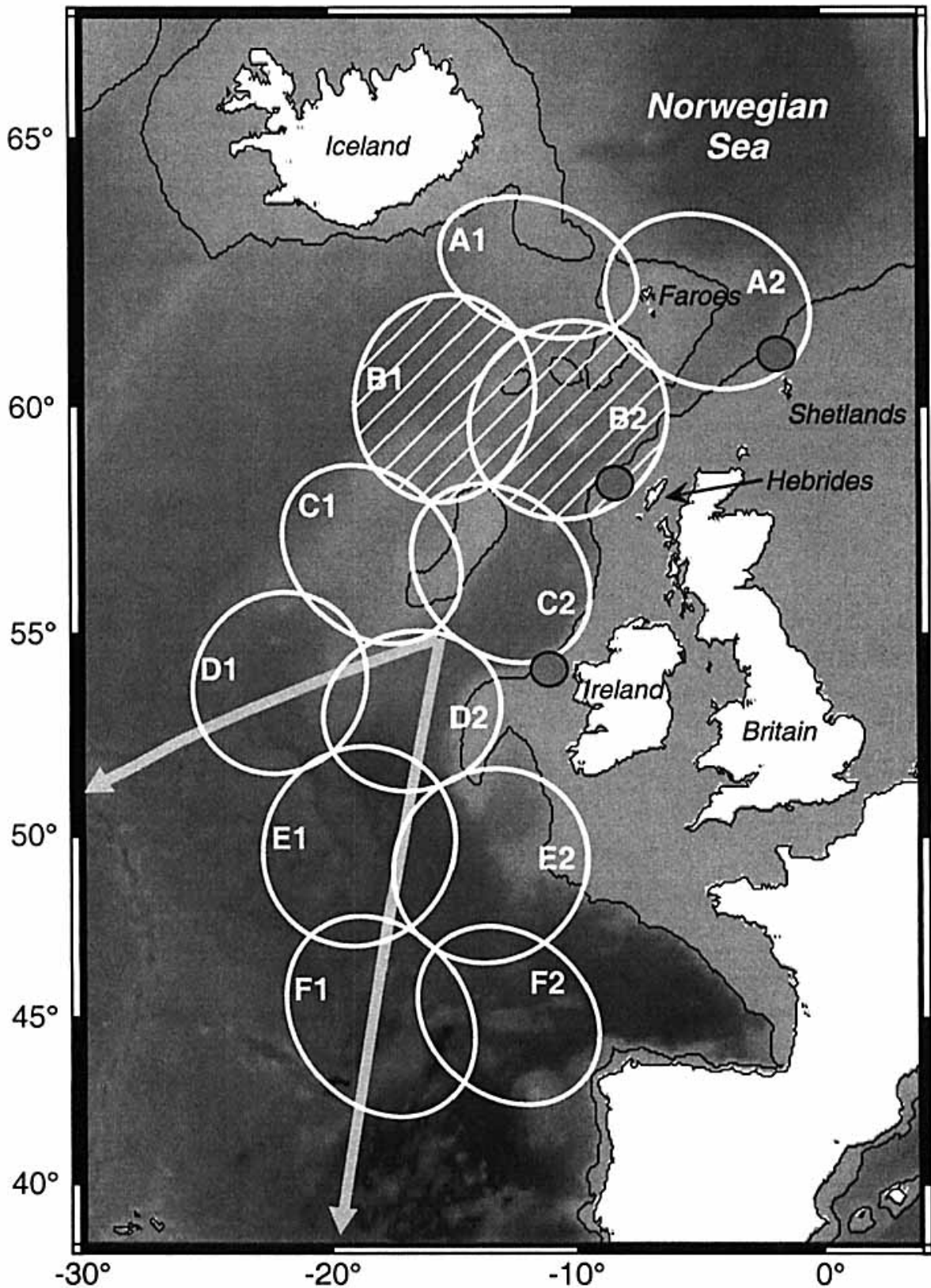

Figure 1. Regions monitored for humpback whale song using passive acoustic arrays. Edge of continental shelf indicated by $500-\mathrm{m}$ depth contour. Increasing depth indicated by darker gray shading. Dark gray circles in Regions A2, B2, and C2 show approximate locations of humpback whale catches, 1908-1914 (Thompson 1928, Brown 1976). Regions B1 and B2 hatched to indicate that acoustic detection data from these regions are negatively biased relative to other monitoring regions. Arrows indicate Great Circle routes from near center of monitoring area to humpback breeding areas in the Caribbean and Cape Verde Islands. 
SOSUS arrays) have been used to detect and track humpback, blue, and fin whales (Clark 1995, Abileah et al. 1996, Stafford et al. 1998, Moore et al. 1998, Watkins et al. 2000).

The continuous, stereotyped pattern of sounds that characterize humpback whale songs (Payne and McVay 1971) represents a particularly useful feature for such monitoring since song is produced at high sound pressure levels (e.g., average broadband source level of $174 \mathrm{~dB}$ re $1 \mu \mathrm{Pa}$ at $1 \mathrm{~m}$, Frankel 1994) and is easily distinguishable from any other sound. Only males sing. Furthermore, presumably because song appears to function primarily as a breeding advertisement (Tyack 1981), most singing occurs during the winter breeding season in the vicinity of the whales' low-latitude mating and calving grounds. However, singing humpbacks have occasionally been detected at higher latitudes, both along migration corridors in winter and spring (Clapham and Mattila 1990, Abileah et al. 1996, Norris et al. 1999), and on feeding grounds in spring, fall, and even mid-summer (Mattila et al. 1987, McSweeney et al. 1989). To date, there has been little effort to detect humpback whale song at high latitudes in winter.

Here, we report on singing humpback whales detected during a two-year program of passive acoustic monitoring using SOSUS arrays in deep water north and west of the British Isles. Based on our findings, and a review of earlier data on humpbacks from British and Irish waters, we suggest that this region represents a migration corridor for humpbacks between feeding grounds to the north and breeding areas in tropical waters, probably in the West Indies.

\section{Methods}

\section{Background and Geographic Scope}

Twelve large overlapping regions north and west of Britain and Ireland were monitored (Fig. 1) using SOSUS arrays operated by the US Navy. These regions cover a latitudinal range of approximately $2,300 \mathrm{~km}$, from $42^{\circ} \mathrm{N}$ to $63^{\circ} \mathrm{N}$. The regions were arranged in six pairs, with each pair consisting of an eastern and a western region located at approximately the same latitude. Each region was identified by an alphanumeric label, such as $\mathrm{A} 1, \mathrm{~A} 2, \mathrm{~B} 1, \mathrm{~B} 2$, etc.; in all cases, 1 is the western and 2 the eastern portion of the region. Pairs of east-west adjacent regions are identified by letters only (e.g., A refers to A1 + A2). The eastern region of each pair (e.g., B2) encompassed deep water immediately adjacent to the continental shelf. Although the regions as shown in Fig. 1 include some areas of relatively shallow water $(<500 \mathrm{~m})$, detections of humpback song by SOSUS are restricted to deeper areas within these regions. Each region was monitored by one or more SOSUS arrays. Although the reporting regions are depicted as being elliptical with well-defined boundaries, the shapes and boundary locations shown in Figure 1 should be considered approximate. The number and locations of the hydrophone arrays used cannot be reported because of military security restrictions.

Acoustic data from the SOSUS arrays were transmitted to an undersea sur- 


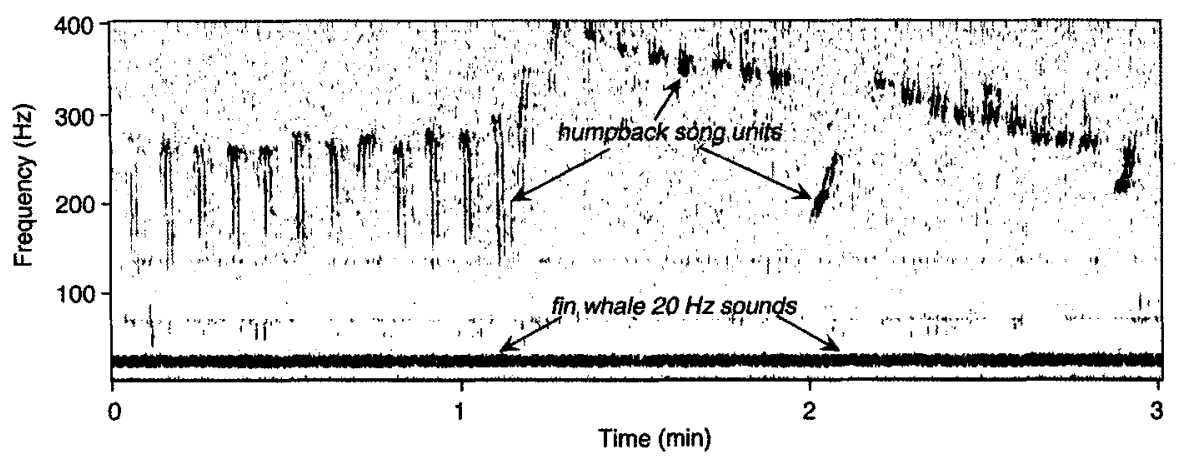

Figure 2. Spectrogram of part of humpback whale song as recorded from SOSUS off British Isles. This particular example was from Region A2 in December 1998. At typical ranges of $>20-30$ miles for humpback song detection, most of song above $400-500 \mathrm{~Hz}$ has been significantly attenuated and is no longer detectable, but lower frequency components are readily evident. Dark band around $20 \mathrm{~Hz}$ is caused by numerous overlapping calls from fin whales. Analysis parameters: $800 \mathrm{~Hz}$ sampling rate, 256-point Hamming window, 256-point FFT, 50\% window overlap.

veillance facility in the UK. Digitized data from each array were processed by a beam-forming algorithm that separated sounds arriving at the array from a series of angular sectors, or "beams," centered on different bearings. Sounds from different beams were displayed on a computer workstation as multichannel sound spectrograms. Although portions of humpback song above approximately $400 \mathrm{~Hz}$ are generally not detected by SOSUS, songs could be identified on the spectrograms by their distinctive low-frequency signatures, which are characterized by repeating sequences of frequency-modulated elements (Fig. 2). Song from any given whale would appeat strongest on one beam corresponding to the bearing from the receiving array to the whale. Since spectrograms of multiple beams are displayed side by side, whales located in different directions from the array that are singing at the same time can easily be distinguished. In most cases a continuous sequence of songs could readily be identified as coming from a single whale. It was generally not possible to determine whether two songs that were separated in time by an hour or more of silence were produced by one whale or by two.

\section{Data Collection}

The data presented here were collected between 1 October 1996 and 30 September 1997 (Year 1), and between 1 October 1997 and 30 September 1998 (Year 2). In Year 2, data were unavailable from late March through early May, due to equipment problems. On one to five (typically one or two) days during each week, an experienced analyst examined sound spectrograms that displayed $24 \mathrm{~h}$ of data from selected beams that monitored the regions shown in Figure 1, and identified humpback songs. For each beam, the number of singing whales detected during each hour of the day was logged on machine- 


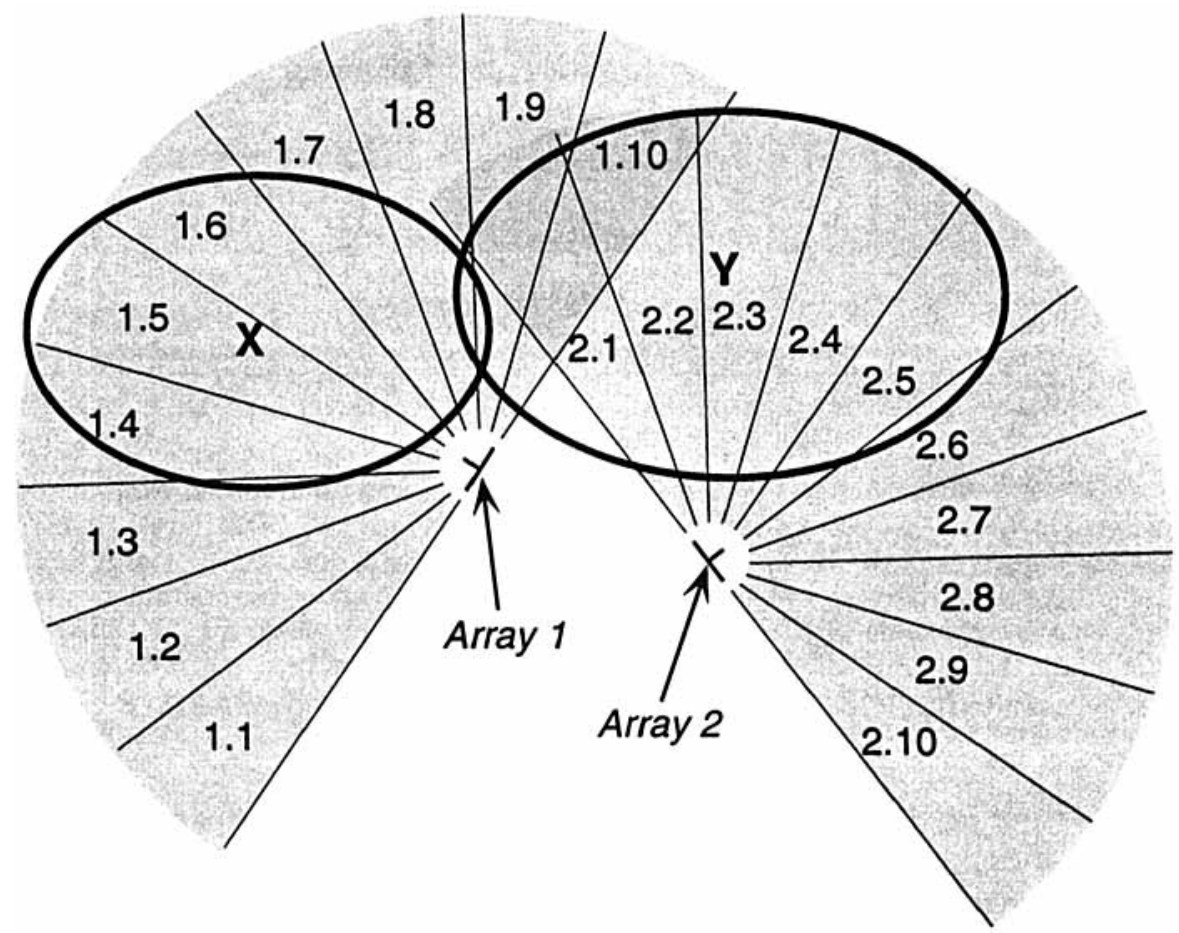

Figure 3. Hypothetical example illustrating determination of spatial sampling effort. Two arrays shown, each with 10 beams; each beam is $18^{\circ}$ wide. Region X is monitored by four beams from Array 1 (beams 1.4-1.8). The total angular space sampled in Region $\mathrm{X}$ is thus $72^{\circ}\left(=18^{\circ} \times 4\right)$. Region $\mathrm{Y}$ is monitored by two beams from Array 1 (beams 1.9 and 1.10), and five beams from Array 2 (beams 2.1-2.5). Total angular space sampled in Region $\mathrm{Y}$ is thus $126^{\circ}\left(=18^{\circ} \times 7\right)$. Acoustic detection density normalizes acoustic detection data from each region to adjust for such differences in spatial sampling effort (see Methods).

scannable forms. Completed data forms were electronically scanned, and the data were merged into a cumulative detection database.

In some cases it was possible to track the movements of an individual whale, eirher by detecting the changes in the bearings to the singer on a single array, or by detecting the animal's song on intersecting beams of two or more arrays. During this study some individual whales were tracked in this way for periods of several hours, up to $24 \mathrm{~h}$ at a time. Security restrictions prohibit detailed reporting of these data. However, results of such tracking are used here to assess general directional trends in whale movements.

\section{Data Analysis}

Detections from each beam were assigned to one of the twelve monitoring regions, depending on the location of the array, and the direction in which 
that beam pointed (Fig. 3). Some regions were monitored by beams from more than one array.

A precise count of the number of whales detected in a region was not possible because we could not reliably determine whether two song sequences separated by several hours of silence were from one whale or two whales. However, we could reliably count the number of whales that were singing in any one hour, provided that they were in different directions from the array, because the songs appeared on different beams. On the rare occasions when two or more whales were singing simultaneously on a single beam, they could usually be distinguished by an experienced analyst by differences in clarity and intensity of the displayed songs (resulting from differences in distance between the whales and the array), and by differences in length of songs. For each day sampled, we used the maximum number of whales detected on any one array monitoring a region in any one hour as an estimate of the minimum number of whales detected in that region for that day. For each region, we report the daily minimum number of whales detected for successive $10-\mathrm{d}$ blocks beginning 1 October.

The daily minimum number of whales detected acoustically is based on data from only one hour out of 24 in each day, i.e., the hour that had the maximum number of whales calling simultaneously. Such reliance on a single value makes this measure more vulnerable to sampling error than a measure based on multiple values.

To compare relative levels of singing activity across regions, we calculated an acoustic detection density (henceforth, "detection density") for each region for successive 10-d blocks. Unlike the minimum whale counts described above, the acoustic detection density is based on all of the data collected throughout a $10-d$ period in a given region. The detection density is a measure of the amount of singing activity detected in a region divided by the sampling effort over a given period. The amount of singing activity detected is measured in units of "detection-hours." The number of detection-hours in one region is the sum, over all beams monitoring the region, of all of the hourly whale counts for the period (see examples in Table 1).

Sampling effort was not uniformly distributed over the twelve regions or among time blocks. Variation among regions occurred because regions were monitored by different numbers of beams (Fig. 3). Variation over time occurred because various events (equipment outages, changes in personnel schedules, etc.) resulted in differing numbers of hours monitored per 10-d block. In calculating the detection density, we compensated for these variations by dividing the total number of detection-hours by a measure of spatial and temporal sampling effort for each region and 10 -d period. For each region and 10-d block, sampling effort was measured in "degree-hours," that is, degrees of arc monitored by all beams that contributed data to that region (Fig. 3), times the number of hours of data that were available. This hourly detection density was then multiplied by 24 to convert it to an average daily value. Thus, for a given 10-d block, the acoustic detection density for a region is calculated as 


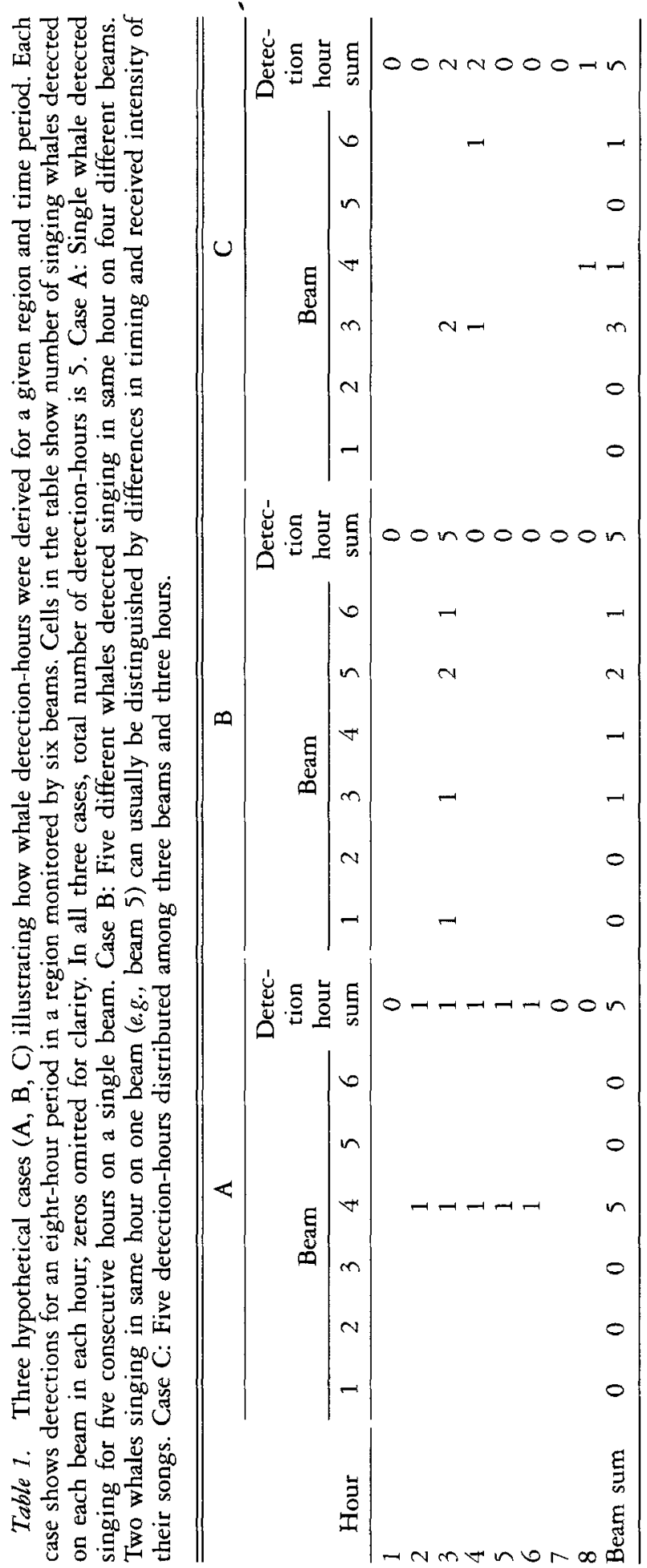




$$
\text { acoustic detection index }=24 \cdot\left(\frac{\sum \text { detectionHours }}{\sum \text { degreeHours sampled }}\right)
$$

The acoustic detection density, in units of whale detection-hours per degreeday, provides a useful normalized measure for comparing the temporal and spatial density of whale singing activity at different times and in different regions. However, there is one exception to this comparability across regions. Because of differences in data collection and processing in Regions B1 and B2, humpback song is less detectable in these regions than in other regions. We thus expect detection densities in these two regions to be negatively biased relative to other regions. Data from Regions $\mathrm{B} 1$ and $\mathrm{B} 2$ are comparable to each other, however, and data from the other ten regions are also comparable to each other.

We estimated the total amount of singing activity in each region over an entire year by calculating each region's annual acoustic detection density, in units of whale detection-hours per degree-day. The annual acoustic detection density is the total number of whale detection-hours for an area over $12 \mathrm{mo}$ divided by the total number of degree-hours of sampling effort, multiplied by 24 .

\section{RESULTS}

Figures 4 and 5 show the minimum numbers of singing humpback whales detected and the acoustic detection density in successive 10-d blocks in each monitoring region. As noted above, the data from Regions B1 and B2 are negatively biased; thus the apparently lower densities in these regions (relative to adjacent areas) are very likely not real. However, the relative seasonal changes in detections in Region B are similar to those observed in adjacent Regions $A$ and $C$.

In Year 1, humpback song was detected between mid-November and midMarch. In Year 2, detections began in mid-October and continued through mid-March; as noted above, no data were available from late March through early May. When data collection resumed in mid-May of Year 2, one to two individual humpbacks were detected singing sporadically in each of Regions A-E through mid-June. From the earliest autumn detections through February in both years, groups of singing humpbacks were tracked moving into and through Regions A, B, C, and D from the north, traveling on generally southwesterly courses. In March the rate of detection declined in the north, and new groups were no longer entering the northern edge of the monitoring area; simultaneously, detections increased in Regions D1 and D2 (west of Ireland), suggesting movement of singing whales into these more southerly regions. No corresponding northward movement was detected. The few singing whales that were detected in May and June of Year 2 did not sing for periods long enough to allow tracking of their movements.

Within each year, there was a significant trend of increasing annual detection density with latitude (Fig. 6) in both western and eastern regions (western 

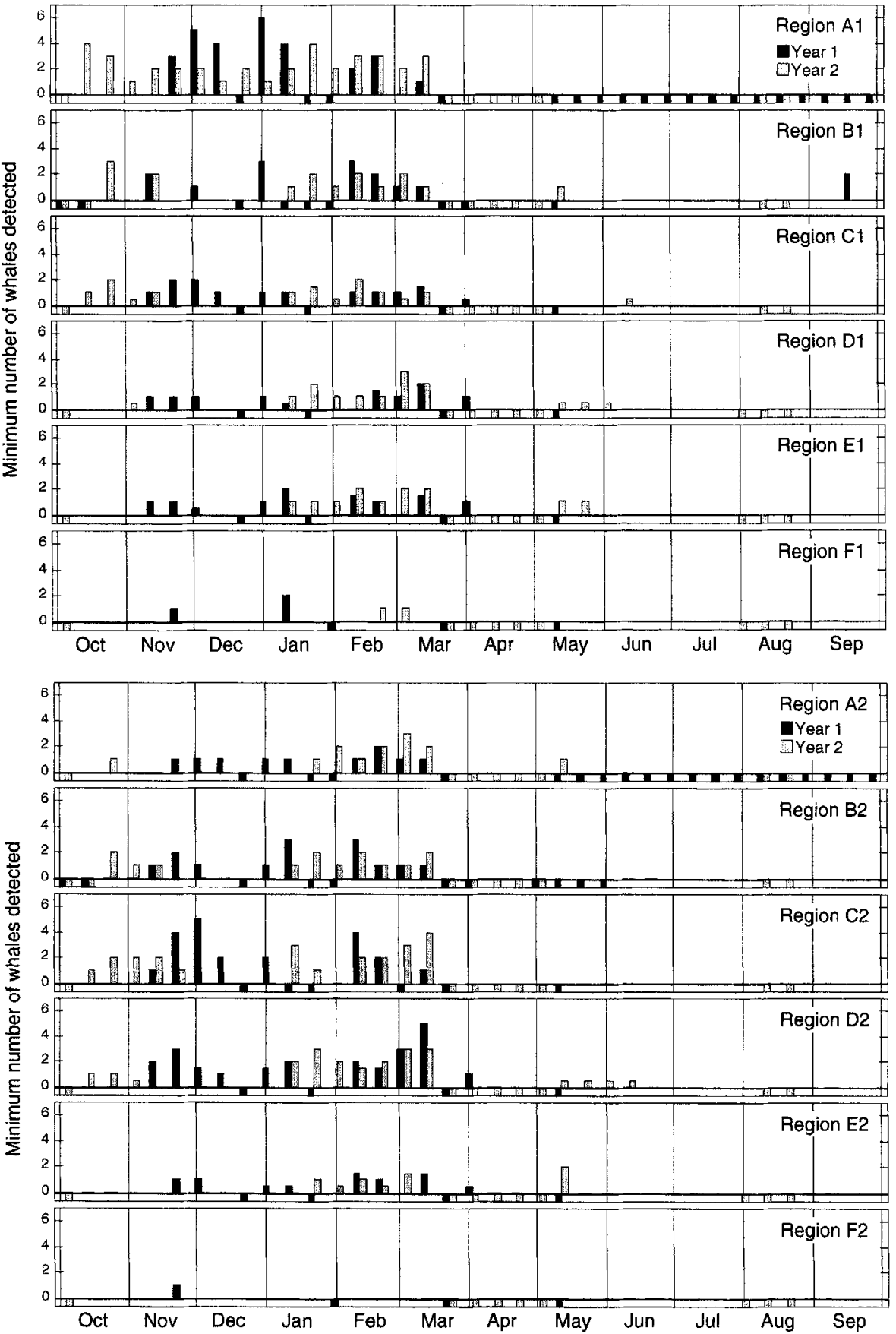

Figure 4. Minimum number of humpback whales detected during 10-d time blocks in each region in Year 1 (black bars) and Year 2 (gray bars). Filled blocks below horizontal axis indicate periods when no data were available. Upper panel: Western regions. Lower panel: Eastern regions. 

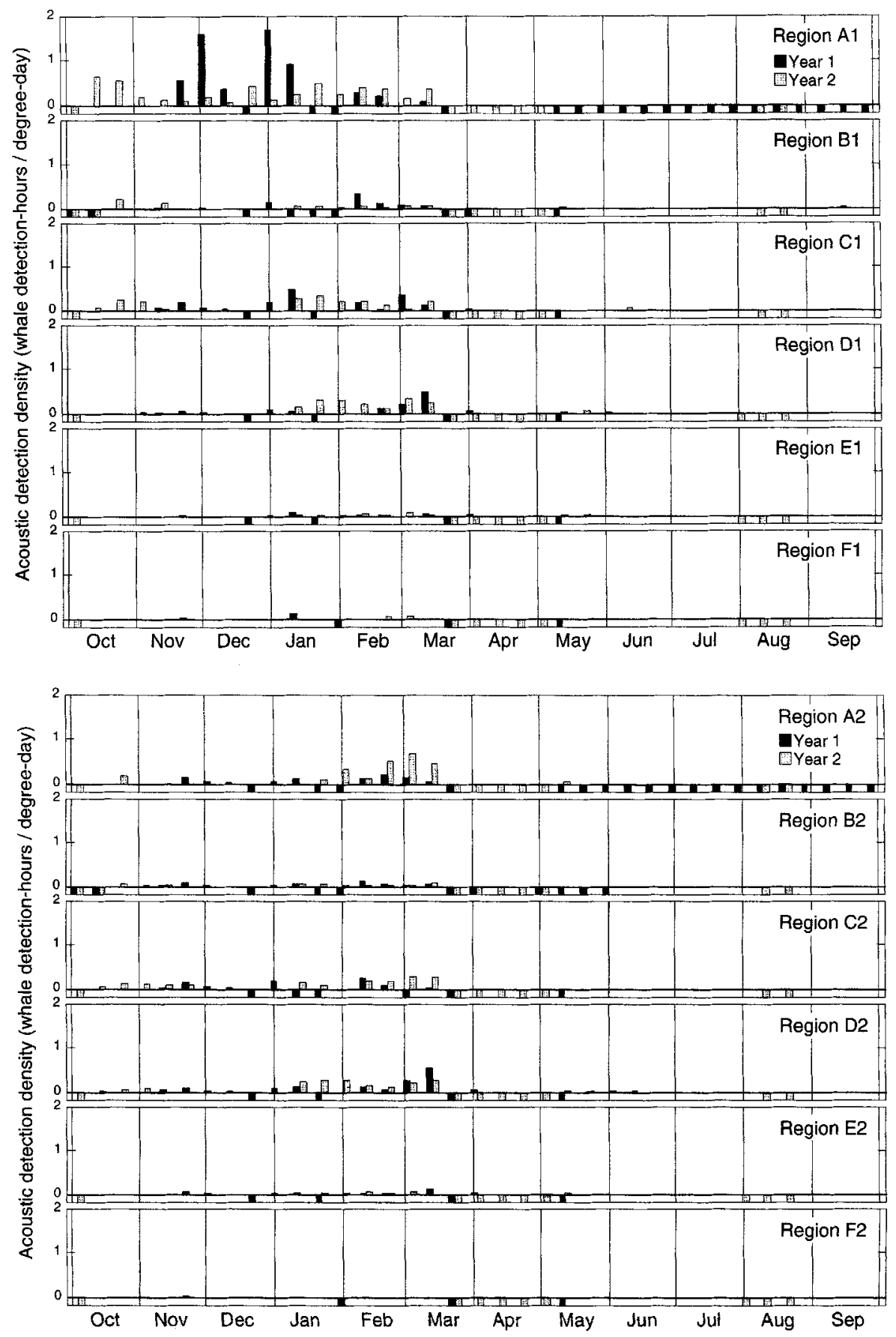

Figure 5. Average daily acoustic detection density for humpback whales during 10-d time blocks in each region in Year 1 (black bars) and Year 2 (gray bars). Filled blocks below horizontal axis indicate periods when no data were available. Upper panel: Western regions. Lower panel: Eastern regions. 

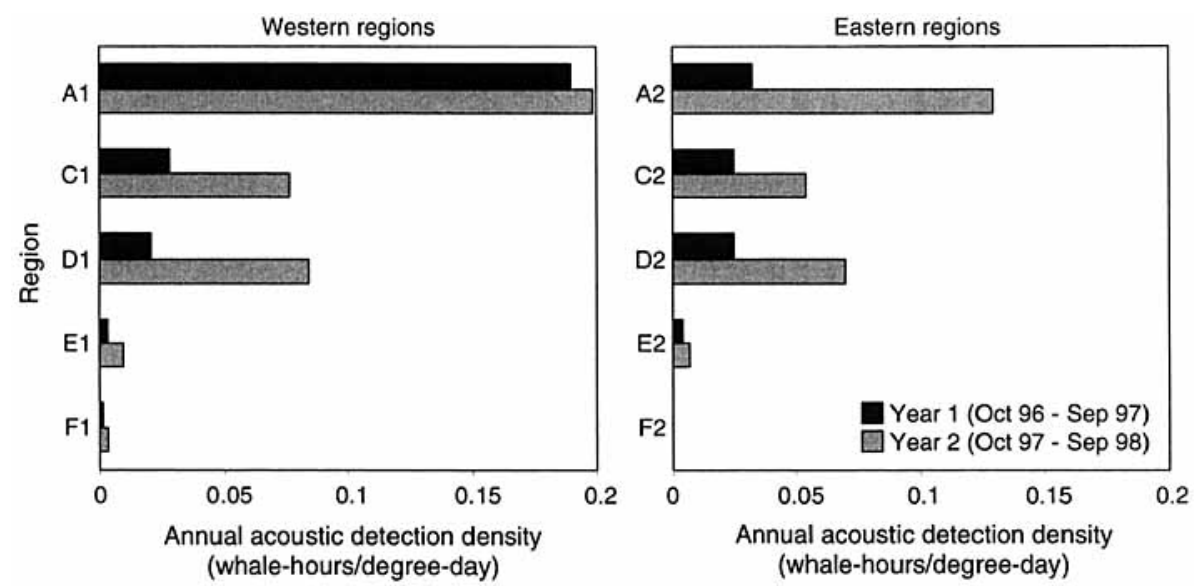

Figure 6. Annual acoustic detection density by region for Years 1 and 2. Data from Regions B1 and B2 omitted because detection rates in these areas are known to be negatively biased relative to other regions.

regions: Spearman's rank correlation, rho $=1.00, P<0.001$; eastern regions: rho $=0.90, P=0.037$ in each year; years analyzed separately). These tests of association excluded data from Region $B$, which are not comparable to data from other regions. The highest detection densities occurred in Region A1 in both years. The low detection densities in Regions $\mathrm{E}$ and $\mathrm{F}$, unlike those in Region B, are not artifacts of any known sampling bias. Overall, the annual detection density in western regions within pairs tended to be slightly higher than in adjacent eastern regions. When data from all regions in both years were included, this tendency was significant (Wilcoxon signed-ranks test, twotailed $P=0.016$ ). This east-west disparity was most pronounced in Region $A$; when data from Region A are omitted, the tendency for western regions to have higher total detection densities than their eastern neighbors was not significant $(P=0.064)$. In Year 1 , peak detection densities in Region A1 were nearly eight times as high as in A2. In Year 2, peak densities were similar between the two regions, but detections were spread out over a longer period in the west than in the east.

In most regions the seasonal variation in detection density was similar in the two years of monitoring. In Region A1, however, peak detection density was substantially lower and detections were spread out over a longer period in Year 2 than in Year 1 (Fig. 5a). In Region A2, detection densities in Year 2 were higher than in Year 1 (Fig. 5b). In other regions, peak detection densities in Year 2 were either slightly lower than, or the same as, those in Year 1.

\section{DisCUSSION}

Our results show consistent detections of singing humpback whales during the fall, winter, and early spring in deep water over a broad arc from around 
the Faroe and Shetland Islands to the area due west of the English Channel, a region in which humpback song has not been previously reported.

\section{Acoustic Detections and Historical Whaling Data}

Data on humpback occurrence off the British Isles are sparse, and consist largely of catch records from the first three decades of the twentieth century (Thompson 1928, Brown 1976). Humpbacks were taken in British and Irish waters during the months of summer, when they were presumably feeding. With a few isolated exceptions, all of the acoustic detections reported here were in winter and early spring. The absence of humpback singing in these areas during summer is not necessarily in conflict with the pattern of occurrence evident in the whaling data, for two reasons. First, since recognition of humpback whales using the SOSUS system is dependent upon detection of song, it is unlikely that such detections would be made during summer given that singing behavior, while not unknown at this time, is uncommon (Mattila et al. 1987, McSweeney et al. 1989). Second, SOSUS detections are confined to deep water; humpbacks feed primarily in shallower water on or at the margin of the continental shelf, and all of the historical catches from British waters were made in summer from such locations. Since the whalers' range did not extend far into deep water off the slope, and since operations did not occur during the months of winter, the catch information and the results reported here sampled different regions and must be regarded as two essentially different seasonal data sets.

\section{Migratory Movements}

The temporal and seasonal pattern of detections of singing humpbacks, and the positions of whales that were individually tracked, both exhibited broad southwesterly movements over the months of October through March. Given the timing, it is very likely that this represents migratory movement. However, neither the feeding-area affinity nor breeding-ground destination of these whales is certain. It is also possible that additional whales occur in winter on the shelf, where they would not be detected with the methods employed here. The absence of a detectable northward migration later in the spring is curious. This may be because whales do not sing this late in the season or because their return route bypasses our monitoring regions, either farther west, or in shallow shelf waters to the east.

With regard to feeding area identity, the whales detected in this study may either represent a resident British subpopulation, or transients from summer feeding grounds in the Norwegian Sea or off eastern Iceland, or a mixture of each. The speculation that most of the whales summer in Norwegian waters is supported by the movement of singing whales southward across the northern margin of Region A. It is also consistent with historical whaling data. Ingebrigtsen (1929) synthesized sighting and catch records of humpbacks from northwestern European waters and concluded that the population exhibited a 


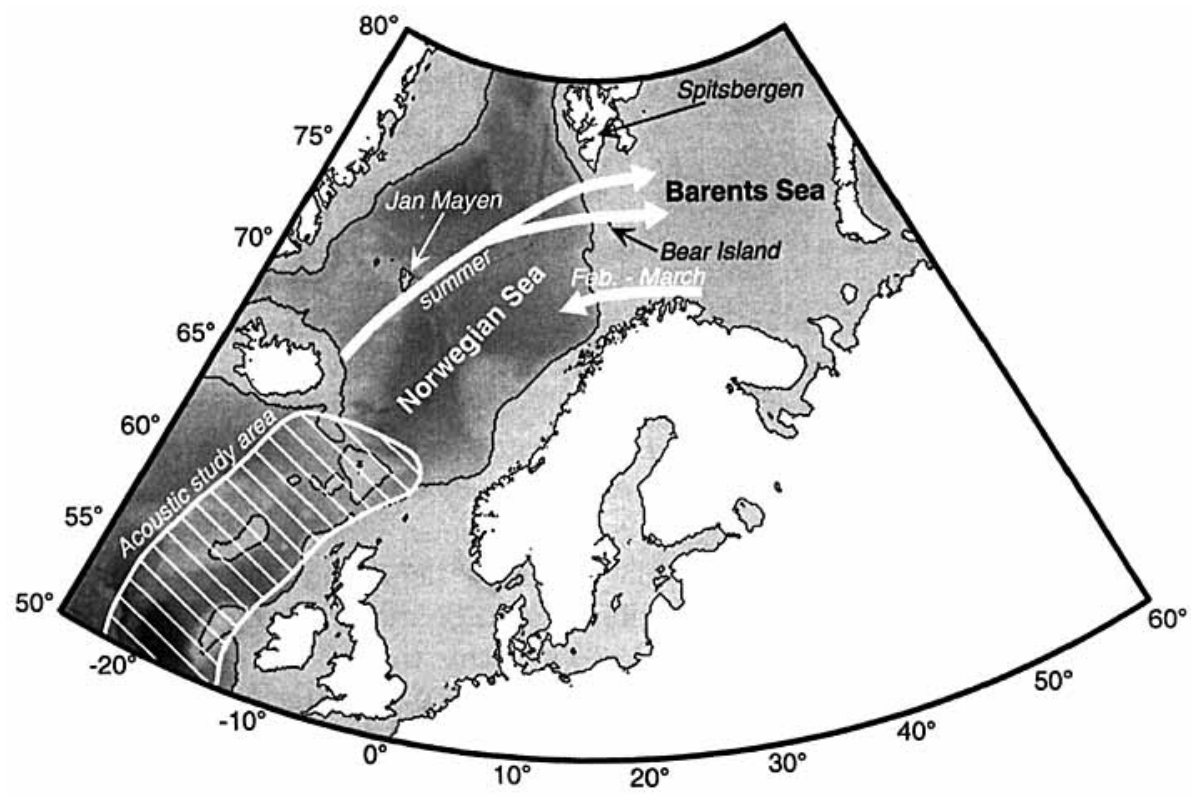

Figure 7. Northeast Atlantic, showing regions where humpback whales occur in summer through early winter. Arrows indicate the general pattern of seasonal movements of humpback whales between Norwegian and Barents Seas proposed by Ingebrigtsen (1929).

circular pattern of movement during the year. He suggested that in summer whales travel from waters east of Iceland north to Jan Mayen, Spitsbergen, and thence into the Barents Sea (Fig. 7). Ingebrigtsen believed that the whales remained in the Barents from September to January prior to beginning a westward migration along the coast of Finnmark (northern Norway) in February and March. Data from sighting surveys and other sources since 1968 provide some confirmation for this circular movement hypothesis; however, far fewer observations of humpbacks were made in the Barents Sea between 1986 and 1989 than in years immediately prior to 1986, a change which may be attributable to a capelin (Mallotus villosus) population crash in 1985/1986 (Christensen et al. 1992).

Recent sighting surveys (since the 1980s) indicate the presence of feeding humpback whales in waters close to or within our northernmost monitoring areas (Region A). These surveys found humpbacks from the Norwegian coast west to at least the Faroes ( $\varnothing_{\text {ien }} 1990$ ). Their present abundance off eastern Iceland (close to our monitoring region A1) is not clear: Sigurjónsson and Vikingsson (1997) report humpbacks off Iceland, but do not specify how many (if any) were observed off the eastern coast. Smith et al. (1999) show a scattering of sightings in the latter area during YONAH surveys. At this point, we can say only that the present data are consistent with the suggestion that humpback whales move west and/or south from Norwegian (and perhaps Icelandic) waters in winter. However, the occurrence of singing humpbacks off 
Britain as early as late October suggests either a timing considerably earlier than that proposed by Ingebrigtsen (1929), or the existence of a second subpopulation.

Whatever their summering ground, where are these whales bound as they move to the southwest in winter? Given what is known of humpback migration behavior (Clapham and Mead 1999), it is probable that these whales are headed for tropical breeding grounds, either in the Cape Verde Islands, or the West Indies. Although the data presented here cannot conclusively discriminate between these alternatives, the variations in detection rate among regions suggest the West Indies as the more likely destination. The very low rate of humpback whale detections from Regions $\mathrm{E}$ and $\mathrm{F}$ in comparison to any of the more northerly monitoring regions would be consistent with a southwesterly migratory movement of humpbacks passing through Regions A through $\mathrm{D}$ on their way to the eastern Caribbean and the West Indies. Whales following a Great Circle route from Region D to the Caribbean would pass to the west of Regions E1 and F1 (Fig. 1), resulting in relatively low detection rates such as those we observed. This pattern would not be consistent with a migratory destination in the Cape Verdes. Most singing whales leaving Region $\mathrm{D}$ bound for the Cape Verdes should have been detected in Regions $\mathrm{E}$ and F, unless the whales follow a circuitous route or cease singing while passing through Regions E and F, both of which seem unlikely (Clapham and Mattila 1990).

Humpbacks detected off Britain between early November and mid-February, traveling a Great Circle route of $5,800 \mathrm{~km}$ at speeds of $100-150 \mathrm{~km} / \mathrm{d}$ (Gabriele et al. 1996, Mate et al. 1998), would reach the West Indies between late December and the third week of March, when many animals are still there (Whitehead and Moore 1982). However, humpbacks that were detected in British waters after the first week of March could not have reached the West Indies until after the last date when humpbacks are seen there in substantial numbers (Whitehead and Moore 1982), unless they traveled much faster than the fastest known swim speed. These late detections suggest that some male humpbacks do not undertake a full migration to the tropics, but instead remain in British or Irish waters during the winter and early spring. Molecular genetic evidence has previously suggested that a substantial proportion of female humpbacks do not migrate to the tropics every year (Brown et al. 1995, Palsbøll et al. 1997).

Movement between the West Indies and the British Isles is quite conceivable in light of a known migratory connection between this breeding ground and Norway, as recently discovered through photographic and genetic resampling of individually identified humpbacks (Palsbøll et al. 1997; Stevick et al. 1998, 1999). Passage through Regions A through D would be quite likely for whales traveling from Norwegian waters to the West Indies.

We do not know whether the SOSUS detections have discovered a seasonal population that has always been present in this region, or whether this is a relatively new phenomenon reflecting what appears to be growth and expansion of the North Atlantic humpback population as it recovers from historical 
exploitation (Smith et al. 1999). Dedicated sighting surveys off the British Isles in summer, in combination with individual identification surveys and genetic analysis, would undoubtedly help to resolve this question.

Our observations provide additional evidence that singing behavior is not confined to tropical waters in winter but is also common on migration (Clapham and Mattila 1990, Abileah et al. 1996, Norris et al. 1999). If song is indeed primarily a breeding advertisement by males for females (Tyack 1981), it is reasonable to suppose that mating occasionally takes place on migration, including in high-latitude waters such as those studied here.

\section{ACKNOWLEDGMENTS}

This research was funded by the Atlantic Frontier Environment Network group of hydrocarbon companies, which consists of Agip (UK) Ltd., Amerada Hess Ltd., ARCO British Ltd., BG E \& P Safety \& Environment Directorate, BP Amoco Exploration, Chevron U.K. Ltd., Conoco (U.K.) LTD, Deminex UK Oil and Gas Ltd., Elf Exploration UK plc, Enterprise Oil plc, Esso Exploration and Production UK LTD., KerrMcGee Oil (UK) PLC, Marathon Oil UK LTD., Mobil North Sea Oil LTD., Phillips Petroleum Company UK LTD., SAGA UK LTD., Shell UK Exploration and Production, Statoil, Texaco North Sea LTD., Total Oil Marine plc, and Veba Oil \& Gas. The project was managed by Mark Tasker on behalf of the Joint Nature Conservation Committee. We thank Fred Wenzl for his early encouragement for humpback acoustic sampling in this region. This work could not have been conducted without the cooperation and support of the U.S. Navy's Commander, Undersea Surveillance (CUS). Wanda Gagnon and Paula Loveday diligently collected all of the data described here. Lieutenant Commander George "Chuck" Gagnon (U.S. Navy) provided expert advice, continuous inspiration and support with many aspects of the work. Carol Carson assisted with data processing and management. Katherine Dunsmore wrote software for generating the regional summaries from the raw detection data. Finally, we thank Whitlow Au, Adam Frankel, Leila Hatch, Richard Merrick, Susan Moore, Fred Serchuk, Peter Stevick, Mark Tasker, and an anonymous reviewer for their helpful comments on the manuscript.

\section{Literature Cited}

Abileah, R., D. Martin, S. D. Lewis and R. Gisiner. 1996. Long-rage acoustic detection and tracking of the Hawaii-Alaska migration. Pages 373-377 in MTS/ IEEE Oceans 96, Vol. 1. Ft. Lauderdale, FL.

Brown M., P. J. Corkeron, P. T. Hale, K. W. Schultz and M. M. Bryden. 1995. Evidence for a sex-segregated migration in the humpback whale (Megaptera novaeangliae). Proceedings of the Royal Society, London B 259:229-234.

Brown, S. G. 1976. Modern whaling in Britain and the north-east Atlantic Ocean. Mammal Review 6:25-36.

Chittleborough, R. G. 1965. Dynamics of two populations of the humpback whale, Megaptera novaeangliae (Borowski). Australian Journal of Marine and Freshwater Research 16:33-128.

Christensen I., T. Haug and N. ØIen. 1992. Seasonal distribution exploitation and present abundance of stocks of large baleen whales (Mysticeti) and sperm whales (Physeter macrocephalus) in Norwegian and adjacent waters. ICES Journal of Marine Science 49:341-355.

Clapham, P. J., and D. K. Mattila. 1990. Humpback whale songs as indicators of migration routes. Marine Mammal Science 6:155-160. 
Clapham, P. J., and C. A. MaYo. 1987. Reproduction and recruitment of individually identified humpback whales, Megaptera novaeangliae, observed in Massachusetts Bay 1979-1985. Canadian Journal of Zoology 65:2853-2863.

Clapham, P. J., and J. G. Mead. 1999. Megaptera novaeangliae. Mammalian Species 604:1-9.

Clark, C. W. 1995. Application of US Navy underwater hydrophone arrays for scientific research on whales. Report of the International Whaling Commission 45: $210-212$

Clark, C. W., and W. T. Ellison. 1989. Numbers and distributions of bowhead whales, Balaena mysticetus, based on the 1986 acoustic study off Pt Barrow Alaska. Report of the International Whaling Commission 39:297-303

Dawbin, W. H. 1966. The seasonal migratory cycle of humpback whales. Pages $145-$ 170 in K. Norris, ed. Whales dolphins and porpoises. University of California Press, Berkeley, CA.

FRANKel, A. S. 1994. Acoustic and visual tracking reveal distribution, song variability, and social roles of humpback whales in Hawaiian waters. Doctoral dissertation, University of Hawaii.

Gabriele, C. M., J. M. Straley, L. M. Herman and R. J. Coleman. 1996. Fastest documented migration of a North Pacific humpback whale. Marine Mammal Science 12:457-464.

InGEBRIGTSEN, A. 1929. Whales caught in the North Atlantic and other seas. Rapp PV Réun CIEM 56:1-26.

Katona, S. K., and J. C. Beard, 1990. Population size, migrations and feeding aggregations of the humpback whale (Megaptera novaeangliae) in the western North Atlantic Ocean. Report of the International Whaling Commission (Special Issue 12):295-305.

KelLOGG, R. 1929. What is known of the migrations of some of the whalebone whales. Annual Report of the Smithsonian Institution for 1928, pp 467-494.

Larsen, A. H., J. Sigurjónsson, N. Øien, G. Vikingsson and P. J. Palsbøll. 1996. Population genetic analysis of mitochondrial and nuclear genetic loci in skin biopsies collected from central and northeastern North Atlantic humpback whales (Megaptera novaeangliae): Population identity and migratory destinations. Proceedings of the Royal Society, London B 263:1611-1618.

Martin, A. R., S. K. Katona, D. K. Mattila, D. Hembree and T. D. Waters. 1984. Migration of humpback whales between the Caribbean and Iceland. Journal of Mammalogy 65:330-333.

Mate, B. R., R. Gisiner and J. Mobley, 1998. Local and migratory movements of Hawaiian humpback whales tracked by satellite telemetry. Canadian Journal of Zoology 76:863-868.

Mattila, D. K., L. N. Guinee And C. A. Mayo. 1987. Humpback whale songs on a North Atlantic feeding ground. Journal of Mammalogy 68:880-883.

McSweeney, D. J., K. C. Chu, W. F. Dolphin and L. N. Guinee. 1989. North Pacific humpback whale songs: A comparison of southeast Alaskan feeding ground songs and Hawaiian wintering ground songs. Marine Mammal Science 5:116-138.

Mitchell, E., AND R. R. Reeves. 1983. Catch history abundance and present status of northwest Atlantic humpback whales. Reports of the International Whaling Commission (Special Issue 5):153-212.

Moore, S. E., K. M. Stafford, M. E. Dahlheim, C. G. Fox, H. W. Braham, J. Polovina AND D. Bain. 1998. Seasonal variation in reception of fin whale calls at five geographic areas in the North Pacific. Marine Mammal Science 14:617627.

NishIWAKI, H. 1966. Distribution and migration of the larger cetaceans in the North Pacific as shown by Japanese whaling results. Pages 171-191 in K. Norris, ed. Whales dolphins and porpoises. University of California Press, Berkeley, CA.

Norris, T. F., M. MCDonald and J. Barlow. 1999. Acoustic detections of singing 
humpback whales (Megaptera novaeangliae) in the eastern North Pacific during their northbound migration. Journal of the Acoustical Society of America 106: 506-514.

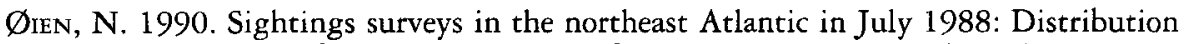
and abundance of cetaceans. Report of the International Whaling Commission 40:499-511.

Palsbøll, P. J., P. J. Clapham, D. K. Mattila, F. Larsen, R. Sears, H. R. Siegismund, J. Sigurjónsson, O. Vásquez and P. Arctander. 1995. Distribution of mtDNA haplotypes in North Atlantic humpback whales: The influence of behavior on population structure. Marine Ecology Progress Series 116:1-10.

Palsbøll, P. J., J. Allen, M. Bérubé, P. J. Clapham, T. P. Feddersen, P. Hammond, H. Jørgensen, S. Katona, A. H. Larsen, f. Larsen, J. Lien, D. K. Mattila, J. Sigurjónsson, R. Sears, T. Smith, R. Sponer, P. Stevick and N. Øien. 1997. Genetic tagging of humpback whales. Nature 388:767-769.

PaYNe, R., AND S. MCVAY. 1971. Songs of humpback whales. Science 173:585-597.

Reiner, F., M. E. Dos Santos and F. W. Wenzel. 1996. Cetaceans of the Cape Verde archipelago. Marine Mammal Science 12:434-443.

Sigurjónsson J., and G. A. Víkingsson. 1997. Seasonal abundance of and estimated food consumption by cetaceans in Icelandic and adjacent waters. Journal of Northwest Atlantic Fisheries Science 22:271-287.

Smith, T. D., J. Allen, P. J. Clapham, P. S. Hammond, S. Katona, F. Larsen, J. Lien, D. Mattila, P. J. Palsbøll, J. Sigurjónsson, P. T. Stevick and N. Øien. 1999. An ocean-basin-wide mark-recapture study of the North Atlantic humpback whale (Megaptera novaeangliae). Marine Mammal Science 15:1-32.

Stafford, K. M., C. G. Fox and D. S. Clark. 1998. Long-range acoustic detection and localization of blue whale calls in the northeast Pacific Ocean. Journal of the Acoustical Society of America 104:3616-3625.

Stevick, P., N. ØIEN and D. K. MatTila. 1998. Migration of a humpback whale between Norway and the West Indies. Marine Mammal Science 14:162-166.

Stevick, P. T., N. Ømien and D. K. Matrila. 1999. Migratory destinations of humpback whales from Norwegian and adjacent waters: Evidence for stock identity Journal of Cetacean Research and Management 1:147-152.

Thompson, D. W. 1928. On whales landed at the Scottish whaling stations during the years 1908-1914 and 1920-1927. Fisheries Board for Scotland Scientific Investigations no III.

TYACK, P. 1981. Interactions between singing Hawaiian humpback whales and conspecifics nearby. Behavioral Ecology and Sociobiology 8:105-116.

Watkins, W. A., M. A. Daher, G. M. Reppucci, J. E. George, D. L. Martin, N. A. Dimarzio and D. P. Gannon. 2000. Seaonality and distribution of whale calls in the North Pacific. Oceanography 13:62-67.

Whitehead, H., and M. J. Moore. 1982. Distribution and movements of West Indian humpback whales in winter. Canadian Journal of Zoology 60:2203-2211.

Winn, H. E., R. K. Edel and A. G. Taruski. 1975. Population estimate of the humpback whale (Megaptera novaeangliae) in the West Indies by visual and acoustic techniques. Journal of the Fisheries Research Board of Canada 32:499-506.

Received: 21 September 2000 Accepted: 19 March 2001 